\title{
Concepções, paradigmas e valores para o desenvolvimento sustentável ${ }^{1}$ Conceptions, paradigms and values for the development sustainable.
}

Francine Pellaud ${ }^{2}$

\section{Resumo:}

O artigo discute os resultado de uma pesquisa sobre a identificação de parâmetros necessários para transmitir ao público o conceito de desenvolvimento sustentável no contexto de uma exposição de museu interativa. A partir da análise de entrevistas com visitantes da exposição identificamos alguns obstáculos individuais, sobretudo relacionados ao envolvimento pessoal requerido na apropriação do conceito. Concluiu-se que os obstáculos estão situados em diferentes níveis, alguns atingindo o desenvolvimento cognitivo e a dificuldade vivenciada pelas pessoas por temer a complexidade, outros mais ligados ao domínio do emocional, da ética, ou para um certo quadro da realidade.

Palavras-Chave: desenvolvimento sustentável, educação ambiental, educação não-formal

\section{Abstract:}

The article discusses the results of research on the identification of parameters for the diffusion of the concept of sustainable development through an interactive museum exposition. Based on the analyses of interviews with museum visitors, we identified some individual obstacles, mainly those related to personal engagement necessary to the appropriation of the concept. We concluded that the obstacles can be situated at different levels, some being related to the cognitive development, some more related to the emotional domain, the ethical domain, or to certain aspect of reality.

Key-words: sustainable development, environmental education, informal education

\footnotetext{
${ }^{11}$ Palestra proferida na Conferência Internacional sobre Ciências Sociais, Havai, 12 de Junho 2003.

2 LDES Laboratório de Didática e Epistemologia das Ciências, Universidade de Genebra - E-mail: francine.pellaud@pse.unige.ch
} 


\section{1-Introdução}

O conceito de desenvolvimento sustentável foi por muito tempo ignorado pela população européia ficando restrito aos discursos políticos, de certo modo, cada vez mais utilizado para justificar as atividades das indústrias privadas. Se esta divulgação permite popularizar o tema, ela não garante no entanto, sua operacionalização .Neste breve artigo apresentamos uma pequena discussão que visa popularizar o tema, sem a pretensão de esgotá-la. De fato, há uma omissão mundial da discussão de temas ligados à Educação Ambiental seja em espaços escolares ou não o que provoca sérias conseqüências para a conceituação geral do desenvolvimento sustentável.

Todos os atores sociais estão envolvidos nesta discussão. A pesquisadora Gro Harlem Brundtland, em 1993, em sua introdução à Agenda 21 retrata o tema:

"As promessas feitas no Rio somente poderão realizar-se a tempo de assegurar nosso futuro caso os cidadãos, as pessoas prontas para sustentar algumas decisões difíceis e pedir a mudança, saibam inspirar seus governos e exerçam pressões sobre eles. "

A mensagem é clara: o desenvolvimento sustentável está nas mãos de cada indivíduo e cabe a cada um lutar para que ele não seja um ideal teórico para o qual a humanidade deveria convergir.

\section{2-Transmitir ao público uma mensagem sobre o desenvolvimento sustentável}

Apresentamos neste artigo os resultados de uma pesquisa desenvolvida sobre a identificação de parâmetros necessários para transmitir ao público o conceito de desenvolvimento sustentável através de uma exposição interativa (Pellaud, 2000). A metodologia aplicada foi composta da análise de entrevistas, conduzidas junto a 140 visitantes pertencentes a diferentes horizontes sócio-culturais não ligados diretamente às questões de Educação Ambiental. A análise das concepções ${ }^{2}$, assim coletadas, permitiu-nos identificar alguns obstáculos individuais, sobretudo sobre o envolvimento pessoal requerido na apropriação do conceito de desenvolvimento sustentável.

${ }^{2}$ Para saber mais sobre concepções e a análise delas, procurar o artigo de Pellaud, F. e Eastes, R-E.

The importance of "presenting " knowledge: The role of the teaching environment in the Allosteric Learning Model.

A análise das entrevistas evidenciou lógicas subjacentes e relações com paradigmas sociais diferenciados. A partir desses resultados conclui-se que os obstáculos estão situados em diferentes níveis, alguns atingindo o desenvolvimento cognitivo e a dificuldade vivenciada pelas pessoas por temer a complexidade, outros mais ligados ao domínio do emocional, da ética, ou para um certo quadro da realidade. Tal trabalho permite situar as dificuldades que a comunicação pública, a difusão de mídia, o ensino, a formação e, de uma maneira mais geral, a mediação de tópicos complexos podem encontrar, requerendo uma implicação/comprometimento? forte por parte do indivíduo. Em qual a comunicação pública de tais tópicos implicam em um forte envolvimento do indivíduo. 


\section{3-Uma noção chave: a responsabilidade}

Além das interações entre desenvolvimento social, econômico e ecológico às quais o conceito normalmente se refere, o desenvolvimento sustentável faz apelo a um quarto pólo: a da reflexão ética.(figura1)

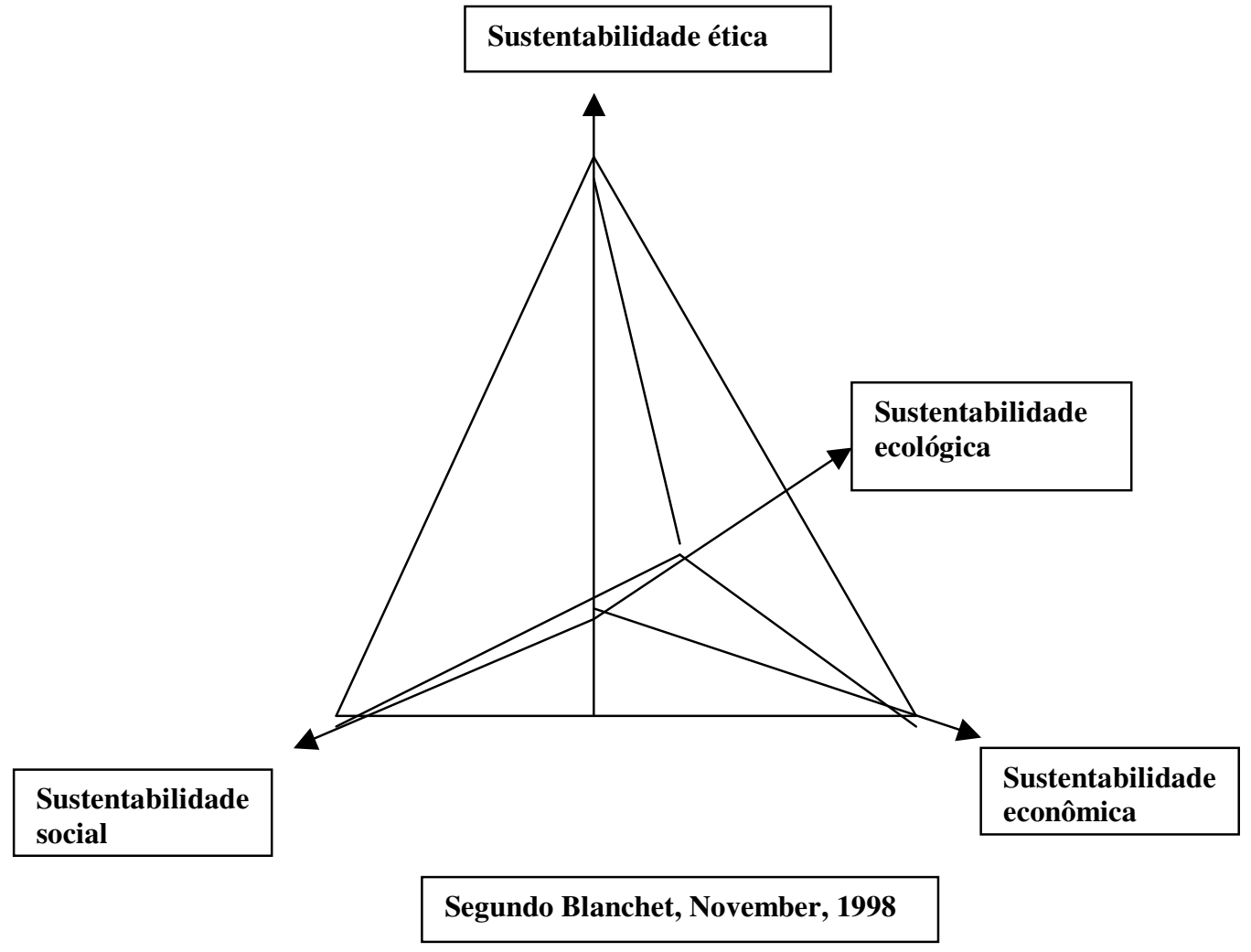

Figura 1 Eixos de sustentabilidade do desenvolvimento sustentável segundo Blanchet, November 1998.

Originada deste último, reencontramos então, a responsabilidade coletiva, mas também individual à qual se refere à citação que destacamos de Brundtland. Porém, muitos obstáculos tornam esta responsabilização difícil. De um ponto de vista do indivíduo, três grandes dificuldades são relevantes. A primeira está relacionada à dificuldade para aceitar esta responsabilidade. Habituados, em países ocidentais, a serem protegidos por seguradoras, e serem defendidos por um sistema jurídico o indivíduo, inevitavelmente tenta acusar "o outro ". É difícil, também, para o indivíduo aceitar as deficiências presentes no ambiente e na sociedade que para ele devem coexistir harmonicamente, pois estão ligadas à sua escolha de vida e consumo. É, então, acima de tudo "culpa" dos outros, do sistema político que deveria tomar "boas decisões", das indústrias que, através de propagandas incitam o consumo excessivo, do estado e dos municípios que não põem à disposição as infra-estruturas adequadas da falta de triagem e reciclagem do lixo são bons exemplos. Não será também "culpa", por exemplo, de oferta de meios mais eficientes de reciclagem do lixo?. 
(figura 2)

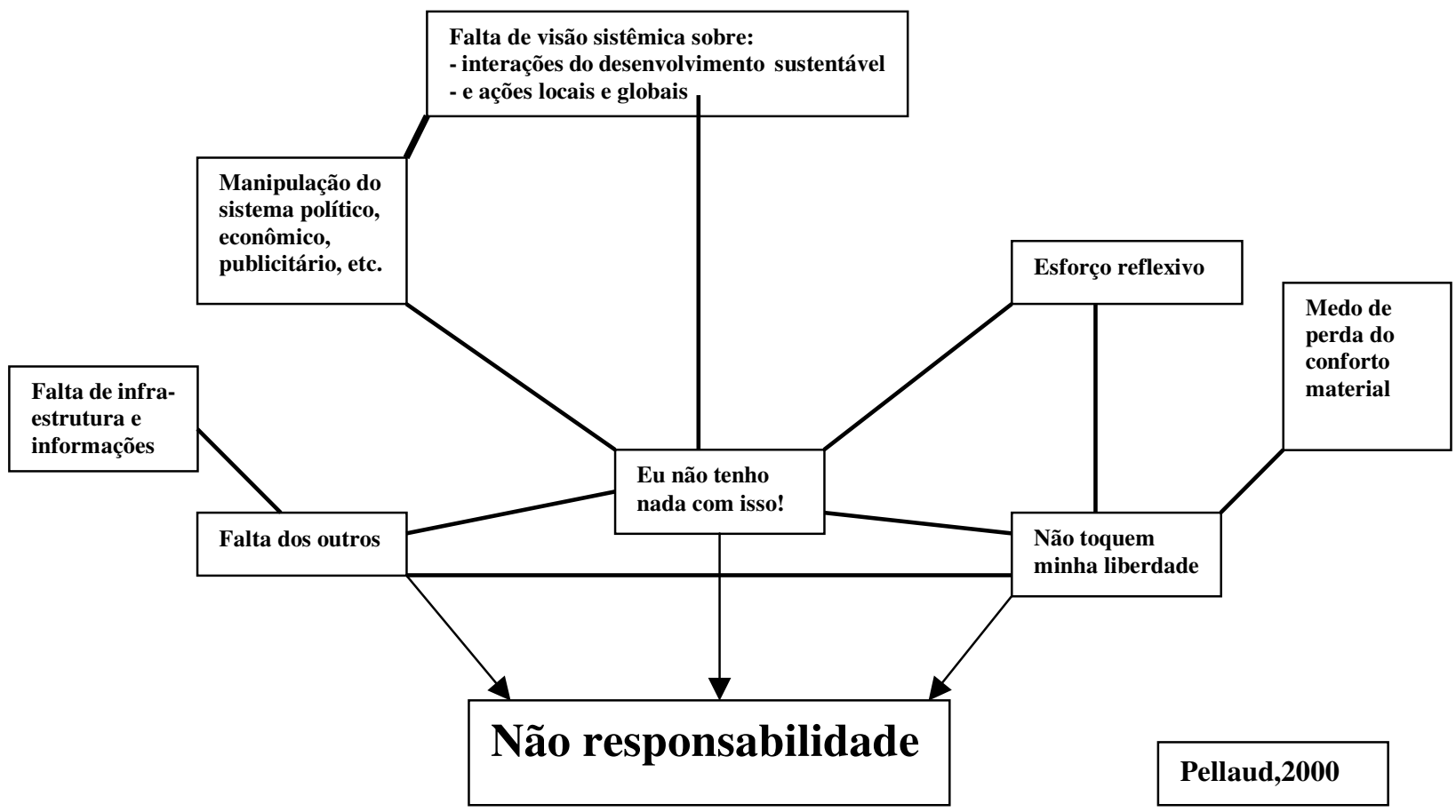

Figura 2: Obstáculos para a responsabilização.

Esta primeira etapa esclarecida, resta que o gesto individual não é discernido como tendo qualquer "poder de influência" na maneira como pode evoluir a sociedade. Se este argumento pode ser uma simples escapatória à vontade dissimulada de não se querer investir, de não se envolver, essa etapa é explicada igualmente pela dificuldade sentida pelas pessoas quanto à complexidade do processo. 
Figura 3 Alguns aspectos da complexidade associada ao desenvolvimento sustentável. Pellaud,2000.

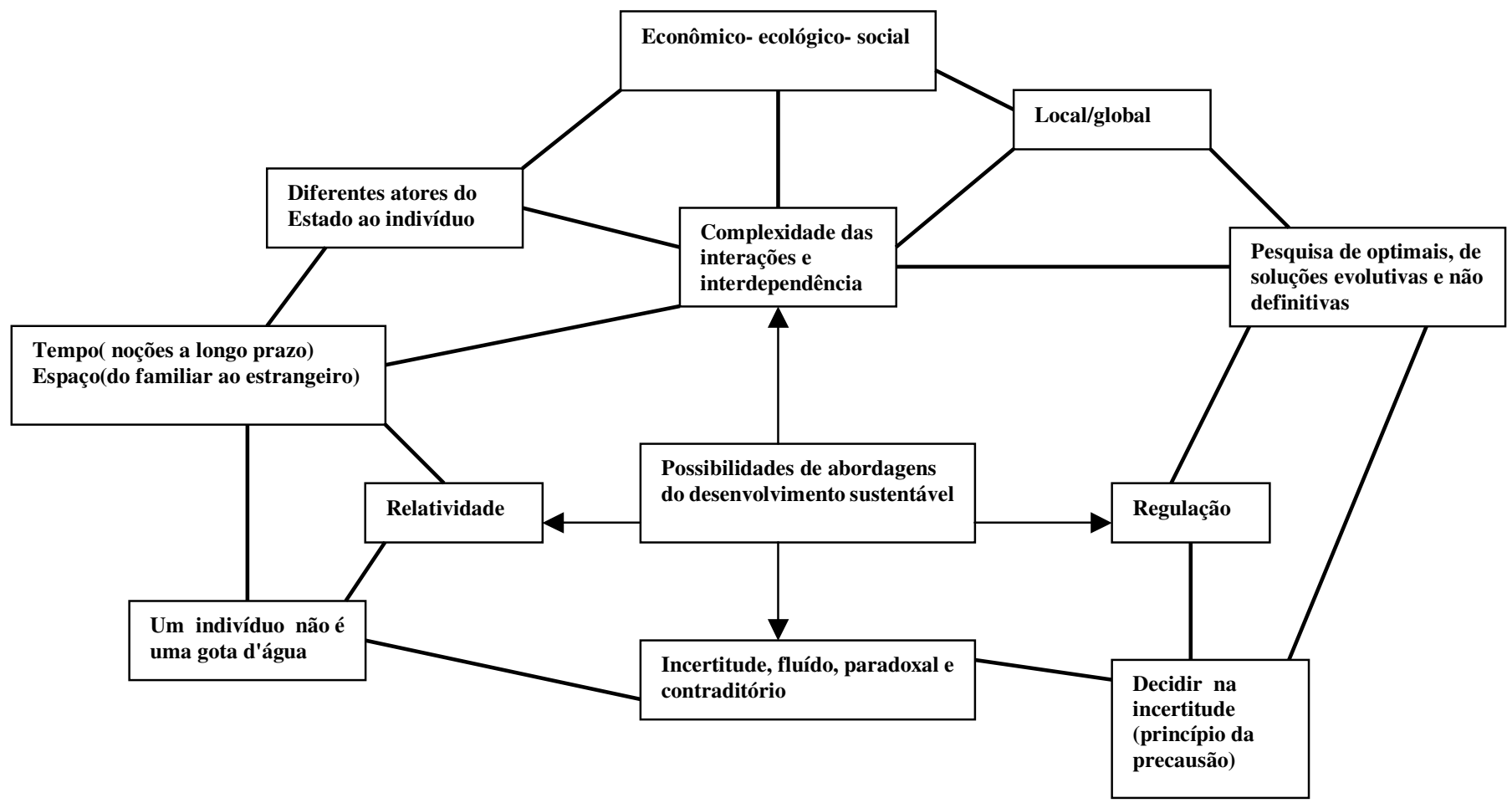

\section{4-A complexidade relacionada aos paradigmas Cartesianos difundidos pela escola}

Realmente, o sistema escolar atual não costuma de maneira alguma a pensar sobre interações e interdependências, conceitos que estão no coração do processo de desenvolvimento sustentável.

Interações entre ecologia, economia e desenvolvimento social, claro, mas também entre os diferentes atores e especialmente, entre a ação local e o desenvolvimento global. A poluição seja da água ou do ar, não conhece os limites nacionais e os investimentos financeiros, mesmo se tratando daqueles, diários, que consistem em escolher tal produto ao invés de outro ou, simplesmente, não consumir, são as bases de decisões econômicas, sociais e ambientais. Um exemplo notável no que diz respeito à força que pode ter "o poder de influência do consumidor "é relevante, pelo menos na Europa, através do desenvolvimento do comércio eqüitativo e dos produtos decorrentes de uma agricultura respeitosa do ambiente. Este aspecto remete-se à noção de relatividade que, abordada de maneira totalmente disciplinar em física, também se aplica aos fenômenos sociais e econômicos. Porque, como evoca Gandhi: "tudo que você faz é irrisório, mas é essencial que você o faça". Mas esta noção de relatividade também se aplica à noção de tempo. $\mathrm{O}$ longo prazo para os economistas varia entre 3 e 10 anos, considerando que o único exemplo de lixos nucleares faz que, para os ecologistas, o longo prazo seja de alguns milhões de anos.

Ao contrário do que ensina a escola, e mais especialmente a matemática, o desenvolvimento extremamente rápido de ciências e técnicas colocam o indivíduo frente à dados que ele nem sempre é capaz de administrar. Até mesmo no seu cotidiano, o indivíduo 
depara-se com situações nas quais ele é obrigado de decidir, sem mesmo dominar todas as implicações conseqüências. É o caso das escolhas alimentares, de saúde, de ambiente, de instalações tecnológicas, etc. Ele encontra-se diante do incerto, do impreciso, do aleatório, do paradoxal, ou até mesmo do contraditório, tantas noções que não aparecem nem em nenhum curso nem disciplinas escolares atuais e para as quais o pensamento Cartesiano prova ser extensivamente insuficiente.

Esta situação, obriga-o a reconsiderar fundações da sociedade Ocidental, acostumada a procurar "A" solução. Solução esta, que no imaginário coletivo será dada pelas ciências e técnicas... Contudo, os programas de computador mais evoluídos e as modelizações mais avançadas ainda não permitem o conhecimento das causas exatas, as conseqüências de um aquecimento climático, a chegada do El Niño, a influência dos OGMs na evolução da flora e de fauna e, conseqüentemente, a evolução da espécie humana, etc.

\section{5-A liberdade individual no nível do paradigma social}

Para finalizar a discussão sobre esse fenômeno de irresponsabilidade, é necessário observar que a liberdade individual, interpretada em seu sentido de "livre arbítrio", subentendendo-se o "como eu quero, quando eu quero e onde eu quero" é uma resistência extremamente forte. O medo do "esforço à fazer", da perda das aquisições materiais e dos privilégios, são demonstrações desta pseudo-liberdade da qual tanto se orgulha a sociedade consumista, que modela as escolhas de vida, individuais e coletivas. Em coerência com este tipo de pensamento, a caridade tem muito freqüentemente moderado o princípio de solidariedade.

Apoiando-se ainda em uma lógica individual, é realmente bem mais fácil se dar "boa consciência" participando de ações caridosas do que investir pessoalmente em uma ação solidária.

\section{6-Mudar nossos modos de raciocínio e ousar abordar os valores}

Incumbência e irresponsabilidade, aproximação Cartesiana e falta de percepção das interações, busca por soluções definitivas e dificuldades em administrar o incerto, livre arbítrio ao invés da liberdade individual, tais são alguns dos paradigmas sociais difundidos pela escola e identificados como obstáculos ao estabelecimento do desenvolvimento sustentável. O que fazer frente à este estado de coisas?

Em primeiro lugar, deixar de ensinar aos alunos conhecimentos nacionais desprovidos de contexto e sem ligações com os problemas atuais. Por exemplo, o aquecimento global é um tópico completamente transversal a todas as disciplinas, incluindo tanto a matemática (cálculos de emissões, de absorção, figuras, estatísticas,etc.), quanto a geografia (países afetados, modificação do ecossistema, desertificação, etc.), a história (Desde quando? Quem participa e por que? Condições políticas, econômicas, etc.) a física e a química (Qual é o fenômeno? Como ele atua?), a tecnologia (Quais outras possibilidades, ao nível de transportes, do aquecimento? etc.) e idiomas (interferindo em todas as pesquisas de informação, mas também através de pesquisas de obras de ficção, por exemplo, etc.). Mais próximo da realidade do aluno estão as questões da gestão da água, 
do lixo, através do ciclo da matéria. São tantos os assuntos que oferecem relações transversais e permitem uma melhor compreensão do mundo através das ligações ofertadas por eles próprios e a implicação individual que podem solicitar. Além disso, trata-se de promover situações aos alunos, nas quais eles possam ter a oportunidade de refletir sobre a noção de valor. Realmente, é necessário que eles possam se posicionar, achar suas referências, saber do que gostam, à que são apegados e porque o são.

Como pretender ter posse do último lançamento em informática e ainda ter um visual sempre na moda, preocupando-se em reduzir as disparidades sociais? Como almejar uma carreira promissora que permita a aquisição de uma Ferrari pensando na redução da fome e da emissão de $\mathrm{CO} 2$ no mundo?

Porque na escola também é preciso se interrogar sobre a maneira como "fabrica-se" o indivíduo... A procura da promoção individual e do lucro pessoal que a sociedade neoliberal continua a incentivar é compatível com o princípio de solidariedade e busca de igualdade defendidos pelo desenvolvimento sustentável? O que significa " qualidade de vida "? É ter um acesso cada vez maior a bens materiais e a um conforto individual ou é necessário ver isto de uma maneira diferente, notavelmente na administração de escolhas de vida, das relações sociais, etc.? Este é um debate no qual a escola teme entrar! Sendo assim, esclarecer valores, sem, portanto, fazer proselitismo, é uma passagem obrigatória para a retomada de questões profundas que a sociedade ocidental necessita realizar.

\section{BIBLIOGRAFIA}

CAPRA, F. (1983/1990) Lê temps du changement, éd. du Rock, Paris

GIORDAN, A. \& SOUCHON, C. (1992) Une Education pour I' Environnement, Z'éditions, Nice.

GIORDAN, A. (1996) (2) Learning: beyond constructivism in The new learning models, coll. Penser et agir, Z'éditions, Nice.

GIORDAN, A. PELLAUD, F. (1999) The state of science teaching in The challenges of science education, Concil of Europe Publishing, Strasbourg

JACQUARD, A. (1998). L' équation du nénuphar, Calmann - Lévy editores: Le livre de Poche.

JONAS, H. (1984). Das Prinzip Verantwortung. Versuch einer Ethik für die technologische Zivilisation, Frankfurt a. M. Suhrkamp.

JONAS, H. (1979-1990). Le principe responsabilité, trad. française, Ed. du Cerf, Paris.

LE BIHAN, C. (1997). Les grands problèmes de l'éthique, Seuil, Paris.

MORIN, E. (1977). La Méthode 1 : La nature de la nature, Seuil, Paris.

MORIN, E. (1990). Introduction à la pensée complexe, ESF éd. Paris. 
MORIN, E. (1999). (2) La tête bien faite, Seuil, Paris.

NUTTIN, J. (1985). Théorie de la motivation humaine, PUF, Paris.

PELLAUD, F. (2000). A utilização de concepções do público durante a difusão de um conceito complexo, o desenvolvimento sustentável, em um projeto de museologia. Tese de doutorado, FAPSE - Universidade de Genebra.

SANT-GEOURS, J. (1987). Eloge de la complexité, Ed. Economica, Paris. 